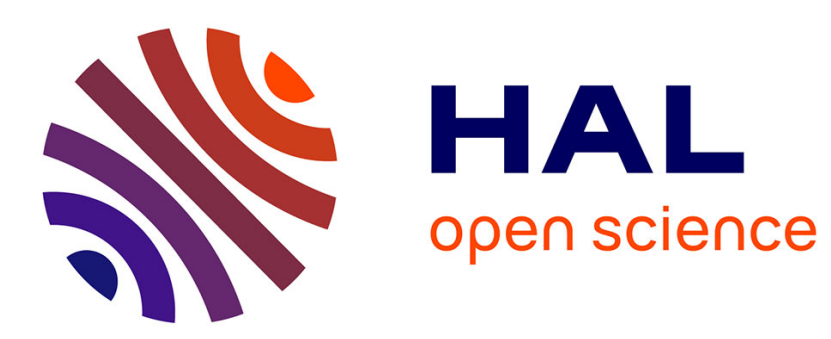

\title{
The Economics of Platforms: A Theory Guide for Competition Policy
}

Bruno Jullien, Wilfried Sand-Zantman

\section{To cite this version:}

Bruno Jullien, Wilfried Sand-Zantman. The Economics of Platforms: A Theory Guide for Competition Policy. Information Economics and Policy, 2021, 54, pp.100880. 10.1016/j.infoecopol.2020.100880 . halshs-03476144

\section{HAL Id: halshs-03476144 \\ https://shs.hal.science/halshs-03476144}

Submitted on 12 Dec 2021

HAL is a multi-disciplinary open access archive for the deposit and dissemination of scientific research documents, whether they are published or not. The documents may come from teaching and research institutions in France or abroad, or from public or private research centers.
L'archive ouverte pluridisciplinaire $\mathbf{H A L}$, est destinée au dépôt et à la diffusion de documents scientifiques de niveau recherche, publiés ou non, émanant des établissements d'enseignement et de recherche français ou étrangers, des laboratoires publics ou privés. 
THE ECONOMICS OF PLATFORMS:

\section{A THEORY GUIDE FOR COMPETITION POLICY}

Bruno Jullien and Wilfried Sand Zantman

Revised, July 2020, No. 1 


\title{
The Economics of Platforms: A Theory Guide for Competition Policy *
}

\author{
Bruno Jullien $^{\dagger} \quad$ Wilfried Sand-Zantman ${ }^{\ddagger}$
}

July 2020

\begin{abstract}
We propose an analysis of platform competition based on the academic literature with a view towards competition policy. First, we discuss to which extent competition can emerge in digital markets and show which forms it can take. In particular, we underline the role of dynamics, but also of platform differentiation, consumers multihoming and beliefs to allow competition in platform markets. Second, we analyze competition policy issues and discuss how rules designed for standard markets can perform in two-sided markets. We show that multi-sided externalities create new opportunities for anti-competitive conducts, often related to pricing and contractual imperfections.
\end{abstract}

KeYWORDS: Networks, Platforms, Markets, Competition Policy.

JEL CLASSIFICATION: L13; L41; L86; D82

\section{Introduction}

Designed primarily as a means of communication, computers and the internet have revolutionized the way we produce and exchange services and goods, whether they are digital

*The authors thanks the guest editor, Yossi Spiegel, and two anonymous referees for their useful comments. They have ongoing consulting relationships with a major European telecom company. They also acknowledge support from TSE Digital Center and from ANR under grant ANR-17-EURE-0010 (Investissements d'Avenir program). B. Jullien is a research affiliate at Positive Competition.

${ }^{\dagger}$ CNRS, Toulouse School of Economics, University of Toulouse Capitole, 1 Esplanade de l'Université, 31080 Toulouse Cedex 6, France, Email: bruno.jullien@tse-fr.eu

${ }^{\ddagger}$ Toulouse School of Economics, University of Toulouse Capitole, 1 Esplanade de l’Université, 31080 Toulouse Cedex 6, France, Email: wsandz@tse-fr.eu 
or not. As a consequence, at the turn of the century a first wave of digital firms like Apple and Microsoft have paved their ways among the major companies in the world. Then, another wave has emerged in the last 15 years, with companies like Amazon, Alibaba, Facebook, Google, Airbnb, Baidu, Booking.com or Uber, also leaping into the front ranks of the world's corporate giants. These companies rely on different business models but all aim at facilitating interactions between individuals and/or firms, and as such they belong to the same general category, now known as platforms. The objective of this article is to take some insights from the academic literature first to understand how platforms compete and second to discuss some elements of competition policy in the digital world.

As a preamble, let us define more precisely what we mean by a platform. ${ }^{\square}$ For this consider, the firms mentioned above: Facebook is a social media website, Google a search engine, Amazon and Alibaba are marketplaces, whereas Uber matches drivers and riders. Despite these very different activities, all these firms have built their models to act as an intermediary. Platforms, just like classical intermediaries, act as matching devices, allowing each side of the market, or at least one side of the market, to find the best agent on the other side - that is, the one that generates the highest surplus. The fact that so much information is available on the internet facilitates this matching process. The emergence of matching platforms is part of the "dis-intermediation" process that has led to potential separation of information management from production/stockage and delivery. Hence, some platforms are pure "infomediaries", focusing on information, acting as aggregators (like TripAdvisor) or sharing platforms (Airbnb). Others (like Amazon Marketplace) provide matching as well as support for transactions and delivery. But a common feature that distinguishes these platforms from traditional resellers is that they allow autonomy for agents on both sides of the market to meet and define trade (see Hagiu and Wright, 2014).

Consequently, potential users of a platform are often concerned about the size of the other side's population to which they will be matched. A seller is more likely to visit a platform if there are many potential buyers, and vice-versa. These network effects explain why the market tends to favor large firms. Even if network effects existed before the emergence of digital firms, for example with telephone communication systems, they often operate differently in the case of platforms. Indeed, potential sellers value a platform more if there are more buyers, not if there are more sellers. So platforms are able to generate or take advantage of inter-group or multi-sided network effects (or indirect network effects) rather than intra-group or direct network effects. Through network effects, every agent, by subscribing to a platform, generates value for some other agents on the platform, which can be positive or negative. This generated value is a common feature of

\footnotetext{
${ }^{1}$ Apple, Microsoft, Alphabet (Google), Amazon, Facebook and Alibaba are now the top-6 firms in terms of market capitalization, whereas in 2007 Microsoft was the only tech firm in the top-10 and ranked 6th.

${ }^{2}$ In this article we shall be concerned solely with multi-sided platforms, and therefore will omit the adjective 'multi-sided'. The term 'platforms' has however been used in different contexts, not all multisided.
} 
platforms and what are now called two-sided markets. ${ }^{\text {[t }}$

Regarding pricing, some groups are important for the other sides, whereas other groups are less important - for example, users are essential for advertisers on a platform while users may care less about advertisers. If a platform can identify each user, and in particular the group to which each user belongs, then it can price the various groups differently. One important subject of study is how platforms set their prices on the different sides of the market, and we will see that the value of the externality is a key component of the optimal pricing formula. The presence of network effects also increases the significance of the belief every agent holds about the future behavior of the other agents. Since the benefit every agent gains depends on the number of agents he can trade with, there is a potential coordination issue when it comes to choosing whether to join a platform or which platform to join. This means that the success or failure of a platform depends to a large extent on the beliefs consumers hold about its future success or failure. This belief dependency explains the additional uncertainty that exists about the fate of platforms, compared with firms in more standard markets. The problem is even more acute when a firm attempts to enter a market where there is already another firm. In contrast to standard markets where agents can be gained individually, it is necessary to attract groups of agents, triggering collective moves and achieving a critical mass. Success here depends on the ability to set smart prices but also to change consumers' beliefs about market dynamics.

The first part of this article aims at reviewing the major theories of platform competition, to understand whether and how effective competition can occur between platforms. There is growing debate about the possible break-up of many so-called "dominant platforms," in particular Amazon, Facebook and Google. So the issue of the economic sustainability of competition in those markets needs to be addressed. More precisely, we will discuss the features that make a market more likely to be monopolized. When the market in which platforms operate is likely to be a monopoly, we discuss the extent to which this market can be contested. Indeed, the fact that a market is a monopoly does not prevent contesting the position of the monopolist. While this discussion will concern markets with "tipping" on one platform, the lessons will also be insightful about the ability of new entrants to emerge in markets that can only accommodate a few firms. If the market under scrutiny is not a monopoly, it will be crucial to analyze in more details the different forms platform competition can take. The most common form to be analyzed is price competition, and we will discuss the likely competitive prices and their normative properties. We will see how price competition between platforms depends on the behavior of the agents, in particular on their decision to stick to one platform - i.e., to "single-home"

\footnotetext{
${ }^{3}$ See Rysman (2019) for references on the estimation of network effects.

${ }^{4}$ According to Rochet and Tirole (2006), the fact that the volume of transactions "depends on the structure and not only on the overall level of the fees charged by the platform" is what defines a two-sided market.
} 
- or to potentially visit more than one platform - i.e., to "multi-home." A last, we will emphasize the role played by consumers' belief in shaping platform competition.

The second part of this article will focus on competition policy issues in two-sided markets. As competition is not solely based on prices, we will have to discuss some non-price dimensions related to the design of the service chosen by competing platforms. Markets where platforms are prevalent have been scrutinized by many competition agencies over the past 20 years and some conducts have been considered anti-competitive. However, the rules generally used to assess the competitive or anti-competitive nature of firms' policies have been designed for standard markets. We will therefore revisit competition policy issues in the context of two-sided markets where the competing firms are platforms. In particular, we will discuss the notion of market power, the essential definition of markets, and the consequences of practices such as tying, exclusionary pricing, exclusivity, foreclosure, collusion, and mergers. We will see that multi-sided externalities create new opportunities for anti-competitive conducts. These new conducts can often be related to some pricing or contractual imperfections, in particular zero-pricing and imperfect coordination between sides.

\section{Theories of Platform Competition}

In the last 20 years, there has been an impressive body of research dealing with platform competition. The objective of this section is to take stock of this literature keeping in mind a few key questions. First, to which extent platform competition should lead to market monopolization? In line with the current debate in many countries regarding the break-up of tech giants, this question is central and clearly deserves to be looked at. Second, when platform competition leads to monopolization, is a form of competition for the market still possible? If it is the case, we can hope that a new and more efficient entrant would be able to replace the current incumbent. If not, then some form of policy intervention may be required. Third, when platform competition does not lead to monopolization, and therefore when there is competition within the market, what are the main features of this competition? Answering this question will allow us to understand when consumers can benefit from competition. We will conclude this first part by discussing the crucial role of beliefs and coordination in shaping competition outcomes.

\subsection{Does platform competition lead to monopolization?}

\subsubsection{Demand-driven network effects and tipping}

In many markets, economists tend to favor competition as the main regulator of economic activity with the caveat that this is not always feasible. In particular, there are some markets where only a few firms can reasonably survive while making a profit. This is usually 
the case when the cost structure favors big firms which produce a large quantity of the relevant good. When there is a large set-up cost, or more generally when cost structure exhibits increasing returns to scale, the market is likely to support only a few firms.

In digital markets, there are some increasing returns to scale as content, once created, is easily duplicated and distributed. But fixed costs are hardly as high as they may be in traditional network industries where monopolization emerges quite naturally. The most striking aspect of digital markets lies in the fact that the average net revenue per user increases with the total number of users because of the existence of demand-driven network effects. As the number of users goes up, the user's willingness to pay also goes up, as well as the price a firm can set for its service. And the competitive advantage of this firm over its rival is increased.

Consider a hypothetical situation where two firms, A and B, act as platforms and compete to attract users. Assuming that connecting people is the only activity of the firms, and abstracting from price competition by assuming that the service is free, means that these two firms are ex-ante perfectly identical. Consider network effects at the firm level and that initially, firm A captures slightly more than half of the market, firm B capturing slightly less. If the switching costs between A and B are not too large, some of B's consumers will switch to A. This move will amplify the difference between the two firms and ultimately all agents will opt for firm A. In the presence of network effects, there is a tendency for markets to favor only one firm, which we refer to as tipping. ${ }^{\text {" }}$

Concentration is efficient because the larger the number of people in the same network, the larger the marginal value created by an additional user. Therefore, it is not so much the cost structure as the demand that can lead to monopolization.

\subsubsection{Elements for competition within the market}

Still, monopoly is not the only possible outcome for platform competition. At least three elements can prevent a market exhibiting network effects from tipping: the existence of some form of differentiation among platforms, the possibility for users to multi-home, and the possibility for platforms to inter-operate.

Platform Differentiation. Most platforms are not simply match-makers, even if the presence of cross-side externalities is a fundamental aspect of their business model. Quite often, platforms also provide services that attract users from one side independently of the actions chosen by the other side. An example are smartphones. Consumers may choose one device based on its quality, e.g. camera or ergonomics, even if fewer applications are available on the operating system (and therefore when the indirect network effects are smaller). Let us return to our example where two platforms compete. Even if most consumers were initially on one platform, some may be willing to switch to another

\footnotetext{
${ }^{5}$ Rubinfeld (1998) was among the firsts to coin this term in the context of network industries.
} 
platform because the quality of service offered by the smaller platform is good enough to compensate consumers for being on the platform with lower network benefits. If the service provided by the smaller platform is valuable for at least some consumers, then this platform may be able to survive even if it attracts fewer consumers. Note that this platform's differentiation can also be achieved by offering different types of services. Note also that in some cases, the simple fact that the network only attracts a specific subset of users (the young for Tik Tok, a video-sharing social networking service, or the runners and cyclists for Strava) can make this platform attractive for consumers. The more differentiated platforms are, at least in the eyes of consumers, the less network effects will matter for the competitive process, thereby enabling several platforms to survive in the market.

Multi-homing. The second element that can mitigate tipping is the possibility for consumers to multi-home, potentially subscribing to more than one platform. As long as there are two active platforms, and some agents choose to join only one, the other agents will have incentives to subscribe to both platforms (this is the case for advertisers in the media industry). Multi-homing allows agents to benefit from large network effects and potentially the services of the two platforms. By contrast, single-homing agents spare some cost but may fail to be connected to some users. Therefore, if some agents can multi-home, there may be scope for stable situations with multiple networks. The question of the sustainability of more than one platform will be driven by the cost structure and demand heterogeneity, in terms of valuation of services and network effects. ${ }^{\text {. }}$

Interoperability. When platforms decide, or are forced, to adopt some interoperability, having more than one platform may not lower social welfare as each user can be connected to all the other agents even if they join only one platform. ${ }^{\square}$ But it is far from clear that all platforms have incentives to accept this interoperability. Let us return to the case of two firms, A and B, assuming that firm A initially captures a larger share of the market than B. Each firm faces the same trade-off. By allowing interoperability, consumers are connected to more people, which increases their utility and therefore the price that can be set. But interoperability also means that both platforms propose the same level of network effects, and this intensifies competition. When a platform is small, it can only

\footnotetext{
${ }^{6}$ There is a link between single-homing/multi-homing and substitutability/complementarity. But since the features of a platform depend on the number/type of agents joining this platform, the notion of substitutability/complementarity is endogenous in a two-sided context. If one side multi-homes, the other sides can view competing platforms are substitutable. But if there is single-homing on the first side, the competing platforms are more complementary on the other side.

${ }^{7}$ The most obvious example are telephone telecommunications. Note that in this case, interoperability has always been considered as crucial. For example, in the USA, after the breakup of the Bell system in 1984, a firm (Bellcore) was established to ensure this interoperability.
} 
gain from interoperability. Conversely, if the platform is large, its users' gain will be limited whereas its competitor will now become more attractive. Consequently, a dominant platform's incentives to accept interoperability will be low (see Crémer, Rey, and Tirole, 2000).

We insisted that, in general, to avoid tipping, platforms must exhibit some form of differentiation, absent any interoperability or multi-homing. But two or more platforms can co-exist despite being formally homogenous if there is some congestion on at least one side, where congestion is defined as a reduction of network benefits on one side when more participants from this side join the platform. If a large platform becomes too congested, then the consumers most affected by congestion may prefer to join a smaller, less congested platform. This possibility is discussed by Karle, Peitz and Reisinger (2020) in the context of housing rental platforms where, while one side of the platform (sellers) values positively additional agents (consumers) on the other side, it values negatively agents on the same side because this intensifies competition. The authors showed that when the degree of competition between sellers is low, the platforms have strong incentives to attract as many sellers and buyers as possible. As they have the same objective and strategy, it is very likely that only one will survive. When competition is intense between sellers, some sellers may prefer to go to a smaller platform to escape competition even if it comes at the cost of reduced demand. Consumers will also split between the two platforms and there will be segmentation of the market. Of course, this reasoning is only valid if consumers single-home. If they could multi-home, sellers would again all compete against each other, which tends to favor agglomeration and ultimately the survival of one platform only. Note also that ex-ante identical platforms may also achieve some ex-post differentiation by adapting their business model. For instance, an ad-free, pay service may coexist with a free, advertising-financed service (see the discussion of Calvano and Polo, 2020, in Section 2.3.1).

\subsubsection{The dynamics of market structure}

How differentiation shapes the long-run market structure depends on the extent of differentiation relative to network effects and on the firms' pricing strategy. Cabral (2011) studies competition between two firms (A and B) which face a constant flow of new consumers and departure of old consumers. One important assumption is that a consumer stays on the same network until departure from the market. Demand is uncertain, as every new consumer can either be biased toward firm A or B, so it is not possible to predict with certainty which network consumers will choose in the future. When network effects are small, the differences in consumers' valuations of the two services prevail and, as in standard competition with product differentiation, the market converges dynamically to a stable situation where the two networks share the market. When network effects are large, Cabral (2011) shows that for a relatively long period of time firm A will have a large market share and firm B will stay small, until a sufficiently large shift in demand 
favors firm B. The market then tips toward B and a new period begins in which firm B has a large market share and firm A stays small, until a new cycle starts again. Hence, the market dynamics exhibits tipping with two characteristics. First, full monopolization doesn't happen; second, dominance is temporary.

An intriguing question is how the small network can survive long enough to take over when demand changes. To answer this, let us consider again the two-firm case discussed above and assume that firm A has captured significantly more consumers than firm B. If both firms set the same price, most new consumers would buy firm A's services. So B will choose low prices to adjust for his low quality whereas firm A will exploit its market power by charging a high price for large network benefits. In short, the exploitation of market power may lead the dominant network to accommodate the presence of a small competitor. An interesting conclusion from Cabral (2011) is that tipping should be understood as a dynamic process alternating periods of competition for the market and periods of dominance of one (or very few) network(s).

This points to a difference between technological economies of scale, as experienced in many traditional network industries, and demand-driven returns to scale, as in most digital markets. In the former case, large fixed costs prevent the existence of small players. But in the latter case there is usually some heterogeneity and scope for horizontal differentiation. Given that entry costs are small in most digital markets, even if a market is prone to tipping there is the possibility for small niche entry exploiting heterogenous perceptions of network effects. For instance, a social network may focus on a small circle. Although there is no threat to the large dominant network in the short run, these small niche competitors will maintain some dynamic competitive pressure on the incumbent as they have the potential to become future challengers.

\subsection{Competition for the market}

We analyze in this section how firms compete when ultimately only one firm operates in a market, the case of competition for the market. ${ }^{\text {. }}$

\subsubsection{Competition with incumbency advantage}

Can competition emerge when there is a firm already in place? There is a common belief that in the digital economy, because of network effects, the leader has such an important advantage that no entrant may be able to replace him. Even though this view is not unanimous (see Evans, 2017), it seems to be shared by many public decision-makers. To

\footnotetext{
${ }^{8}$ Most of the economic literature has focused on the case where the market tips toward a single platform. Some insights should carry on to the case where the market concentrates on a few winners, although this has drawn less attention. What matters is that there is not much competition between this platforms, as Booking vs. Expedia, or IOs vs. Android
} 
see when and how the dominant firm could be replaced by a new one, let us follow Halaburda et al. (2020) and consider two competing platforms, called A and B. Each platform offers a good that has a different level of quality -which is given here- and in addition provides network benefits increasing with the number of users on the same platform. We assume that network effects dominate quality effects, that is, for equal prices of the two platforms, the quality differential is not large enough to compensate for the network effect if all the agents choose the same platform. Despite this assumption, there is scope for competition when dynamics is fully taken into account. When consumers choose a platform, they do not know what other users will choose and the resulting equilibrium depends on the beliefs held by the agents about others' choice. Halaburda et al. (2020) rely on the notion of a focal platform to solve for this indeterminacy. A focal platform is one that every single agent believes will be chosen by the other agents when there is some indeterminacy. In this dynamic environment, the focal platform at any date is assumed to be the platform that was dominant the date before. This assumption is intuitive as the dominant platform enjoys what is referred to by Biglaiser and Crémer (2020) as an "incumbency" advantage. ${ }^{.}$While the incumbency advantage creates some barriers to entry, they may be weakened by dynamic competition considerations. The reason is that the prospective benefits of gaining future incumbency advantage for a superior quality entrant are larger than the prospective benefits of a lower quality incumbent preserving its position. Hence a high-quality, forward-looking entrant may be willing to sacrifice more in current competition than the low-quality incumbent.

Let us now assume that platform $A$ is focal and consider a simple one-period game. Platform A can then stay dominant even if it offers a lower quality than platform B. If $B$ offers a price equal to the marginal cost per user (that is, the minimum price that does not generate negative profit) and A sets the same price, then all consumers strictly prefer to stay with A, even if B has superior quality. As they expect other consumers to stay with A, consumers compare A -with some network effects across all individuals- with $\mathrm{B}$-with a higher quality. According to our assumption, the network effects dominate so all consumers will choose A. A can even choose to raise its price, at least to a level equal to the perceived difference between the network effects and the quality effects. Suppose now that there are two periods. At the beginning of period 2, there is a focal firm which is the winner of the first-period competition. As we have discussed before, in a one-period setting, nothing can prevent the focal firm from winning the market. The meaningful analysis should then be on what occurred before this last period.

At the beginning of period 1, suppose that $A$ is focal. B knows that if it sets the same price as A, it will not be able to win the market. But winning the first period market guarantees that it will win the second period, so B is willing to sacrifice a lot initially. If

\footnotetext{
${ }^{9}$ See also Biglaiser et al. (2020) which focuses on consumer's behavior and show that the incumbency advantage is increased when consumers have multiple opportunities - rather than one - to migrate from one platform to another.
} 
there are more than two periods, it is even easier for a more efficient entrant to overtake a less efficient incumbent. As soon as the entrant becomes the focal firm, there will be no way for the former incumbent to displace it. The more efficient firm will then be able to make some positive profit over a longer period, inducing this firm to be more aggressive initially. In short, in a dynamic framework, an initial advantage is not enough for a less efficient focal firm to maintain its dominant position. The higher the quality of the potential entrant, and the more periods the competition will last, the more aggressive the potential entrant will be at the earliest date in order to benefit for as many possible periods from its superior quality. If dynamics needs to be taken into account in the analysis, it is because some current losses can be recovered in the future but, at the same time, it is also because it may affect consumer beliefs and the relative position of the two firms with regard to incumbency advantage. ${ }^{\text {[1 }}$

\subsubsection{Competitive pricing for the market}

Whereas Halaburda et al. (2020) focus on the role of dynamics in restoring efficiency and countervailing unfavorable beliefs, Caillaud and Jullien (2001 and 2003) look at the role of differentiated tariffs across sides. These contributions analyzed how an incumbent and a potential entrant optimize their prices in order to respectively protect or conquer the market. Caillaud and Jullien (2003) consider situations where the platform's only role is to match agents, even if the matching technology may be imperfect. In their model, there is no standalone value and therefore no utility gained on top of the utility obtained when two agents match. The agents originate from two different groups, called 1 and 2. Any match between a group-1 agent and a group-2 agent generates a value for both agents. And platforms can use subscription fees as well as transaction fees.

When every agent can choose at most one of the two platforms (single-homing case), Caillaud and Jullien (2003) show that the incumbent $(I)$ is able to prevent entry. ${ }^{\text {W }}$ Still, this comes at the cost of profit dissipation, and the profit vanishes to zero. Note first that it is optimal that all agents join the same platform since the probability of a match is maximized. Suppose that initially, all agents subscribe to platform $I$, so any individual agent considering moving to the entrant $E$ should be compensated. But attracting only one agent would not be enough, so $E$ should separately convince many agents from one side to switch. If $E$ were able to do that, agents from the other side would have no choice but to also join this new platform. Since attracting the first group of agents is costly, $E$ should recover this cost by charging the final transaction at the maximal price. Strategies that subsidize participation on one side and recover the loss with the induced revenue

\footnotetext{
${ }^{10}$ This bears a similarity with the case of switching costs; see Farrell and Klemperer, 2007, as well as Biglaiser et al., 2013.

${ }^{11}$ Caillaud and Jullien (2003) did not cast their analysis as an entry deterrence game but as a simultaneous pricing game. Nevertheless, the maximal profit they derive coincides with the profit of a focal Stackelberg leader.
} 
on the other side are called 'divide and conquer' strategies and they are sometimes the only way for a platform to pave its way into a market. But it is unlikely that $I$ will accept the loss of its customers with no reaction. The optimal way for $I$ to prevent entry is to make sure that all sides remain faithful. It will then charge the maximal price for the final transaction, just like any entrant would do, but also redistribute this money ex ante by subsidizing subscription to its platform. In this way, I can deter entry.

The situation in which agents may opt for more than one platform (multi-homing case) leads to slightly different results. When the value of additional matches outweighs the cost for search by an additional platform, multi-homing is efficient and two platforms can operate profitably on the market. Note that the two platforms are different ex ante, $I$ being the focal platform, so they will have different strategies and profits. I will make sure that $E$ can only operate as a second source, that is $E$ will realize the transaction only when the match has failed with $I$. I will make a larger profit than $E$, the latter being only able to capture the marginal value created by a second platform. When multi-homing is not efficient, $I$ can prevent the entry of a new firm and still make a positive profit. This is achieved by setting a transaction fee equal to zero. In this case, platform $E$ cannot subsidize the agents on one side at the registration stage as there will be no way to recover this money at the transaction stage if users multi-home to trade on I's platform. To sum up, there is an incumbency advantage in two-sided markets but the possibility for an entrant either to use a divide-and-conquer strategy or to act as a second source when multi-homing is efficient reduces the strength of this advantage.

As a complement, let us remark that Caillaud and Jullien (2003) focus on the case where there are only inter-group externalities. Belleflamme and Toulemonde (2009) have shown that intra-group externalities (for example congestion on one side) have a dual effect on the ability of an entrant to overtake an incumbent. On the one hand, it is easier to attract some agents from the congested side since these agents are ready to pay a premium to be in a small group. On the other hand, when the number of agents from the congested side is low on a given platform, it is hard to convince the other side to join this platform. Moreover, Caillaud and Jullien (2003) focused on pure intermediaries, where value is only generated when two sides are on board. Jullien (2011) extends the analysis to situations where the standalone value offered by a platform is large and shows that a divide-and-conquer strategy by an entrant is more effective at overcoming the incumbency advantage.

To which extent can we believe that effective competition for the market is feasible? As with most network goods, beliefs are crucial and provide a key advantage to the incumbent. Still, if the horizon is long enough, an incumbent's position can be contested by an entrant of superior quality, provided it has enough financial resources. Taking explicitly a multi-sided approach does not fundamentally change the conclusions. Entrants can try to focus on one side, using a-divide-and-conquer strategy, to lower the cost of entry. But the presence of different groups also lowers the cost for the incumbent to deter this 
entry. This question relates to the debate on exclusionary pricing that will be discussed in Section 3.2.

\subsection{Competition within the market}

In this section, we are interested in the competition between platforms when the market structure has stabilized, that is when consumers have coordinated on a stable market allocation with more than one platform. ${ }^{[1]}$ Despite network effects, this competition within the market occurs either because of platform differentiation-making a distinction between product and business model differentiation-or because of multi-homing. ${ }^{\text {[IJ }}$

\subsubsection{Platform differentiation}

Platform differentiation can be based on the type of product proposed or platforms can differentiate by adopting different pricing strategies or different business models. We look at these two approaches each in turn.

Armstrong (2006) follows the first approach, focusing on exogenous product differentiation. This article considers duopoly competition between platforms that sell a horizontally differentiated consumption good with two-sided network externalities and intrinsic values to consumers. There are two sides ( 1 and 2 ) interested in the good who care about the other side's demand for the good they buy. Preferences over the two goods are modeled by means of the Hotelling model, and each side single-homes. Armstrong (2006) characterizes the equilibrium prices set by the two platforms, and analyzes the role of network effects in shaping these prices. A key insight from Armstrong (2006) is that indirect (cross-sides) network effects tend to increase the elasticity of demand perceived by each platform on both sides of the market. Higher elastic demand means that increasing one price induces a higher loss of sales on both sides of the market. When a consumer on side 1 leaves the platform, network externalities are reduced on the other side, inducing lower demand on side 2; and, by a feedback effect, lower value and lower demand on side 1 . As a consequence, firms refrain from increasing prices and competition is more intense. To put it differently, there are three reasons for a platform to attract a new customer. First, this platform can earn a markup, as in any market. Second, it increases the price the platform can charge to the other side, because of higher network effects. Third, it reduces the attractiveness of its competitor, who lost a client, and offers lower network effects. So, the optimal price is given by

\footnotetext{
${ }^{12}$ Coordination may result from the market structure itself that may not be prone to mis-coordination of consumers and multiple equilibria. It may also result from an assumption that ensures some minimal efficiency in consumers' coordination preventing large gains caused by reallocation of demand across platforms from being wasted.

${ }^{13}$ There is no much work studying platform competition with interoperability.
} 


$$
\text { price }=\text { cost }+ \text { markup }- \text { value created on other side }- \text { competitor value destroyed } \text {. }
$$

Note that Armstrong's analysis is restricted to the case where there are two platforms and two sides. But the intuition is more general. As long as network effects are not too large, Tan et Zhou (2017) show that the pricing formula derived by Armstrong can be generalized to the case where there are many more sides and many more platforms.

The possibility of competition on the market relies on the presence of heterogenous standalone values, as network effects alone tend to generate tipping. But it is difficult for an agent to guess how other agents value each platform. This raises the question of how one can account for this uncertainty about the others' preferences and therefore their willingness to join one of the platforms. This issue has been studied recently by Jullien and Pavan (2018) in a model that shares many features with Armstrong (2006). The additional twist comes from the fact that agents can have different beliefs about other consumers' preferences and therefore about the number of people who, for given prices, could join the other side. To put it differently, it is assumed that the average preference in the population is unknown and can favor either platform. And each agent will use his own taste parameter to update his belief on this average preference and guess likely participation levels on each platform. Let us consider the case of aligned preferences (positive correlation of preferences across sides). In this case, an agent from side 1 with a strong preference for a platform anticipates that many agents on the other side will also have a strong preference. Any price increase on that side will discourage the weakest-preference consumers from buying and thereby increase the marginal agent's belief about the other side's willingness to participate. Because inframarginal agents are more optimistic about the value of participation than marginal agents, fewer agents are discouraged by the price increase than if all agents shared the same beliefs. In other words, in the case of aligned preferences, the demand elasticity is lower when consumers are uncertain about demand. Each platform can set higher prices. And the reverse holds when preferences are negatively correlated across sides. A consequence of these findings is that, in the simple case of single-homing, platforms can alter the intensity of competition by manipulating the information flow to consumers. By giving more or less information about the taste of the different sides for their good, firms can change the consumers' beliefs and therefore equilibrium prices. Communication campaigns, e.g. advertising, show-rooming or free trial, that inform users about the product may then have an anti-competitive effect on prices that ultimately hurts consumers. Likewise better information about realized participation on each side may soften competition.

An alternative to differentiation in products is for platforms to differentiate their business models. Adopting different price skewness to court different segments from competitors on each side of the market is one way to propose a different value than competitors. An illustration is provided by Ambrus and Argenziano (2009) who investigate the condition for the existence of asymmetric networks, as for example, in the market for online job search in the US or in the credit card industry. They assume that on each side, 
there are two types of consumers, some who value large networks highly and a large mass of others who have a low valuation for large networks. Each platform's optimal strategy is to set a low price on one side (1 for example), in order to attract the large mass of consumers with low valuation and set a high price on the other side (then 2). If one platform proposes low prices on side 1 and high prices on side 2, the other platform should do the opposite and propose low prices on side 2 - because there are many agents still free - and high prices on side 1 - for the consumers who value being connected to many agents from the other side. In the case of online job search, there will be two active platforms, one with more job posts and the other with more job candidates.

Competing firms can also adopt a business model that is attractive to a specific set of consumers. Calvano and Polo (2020) study this possibility in the media market. They showed that if one media outlet chooses an Free-To-Air business model, the other may have some incentives to choose the Pay-TV business model. When one media increases the level of advertising and reduces the viewers' subscription fee, it induces the other to do the reverse - that is, to decrease the level of advertising and increase the viewers' subscription fee. This comes from the fact that the two media are substitutable channels for conveying the same advertising content when consumers view the two outlets. The value of pursuing the same strategy is therefore reduced.

Even if most models focus on price competition, firms can also compete in other dimensions on the Internet. For example, Casadesus-Masanell and Hervas-Drane (2015) propose an analysis in which firms provide the same basic service and then compete on price and information disclosure. Firms will opt for different levels of information disclosure, thereby achieving a vertical differentiation of their products. It shows again that different possible models (paid/free) can co-exist in the same internet market.

\subsubsection{Multi-homing}

The previous contributions share the important assumption that each agent could only join one platform. How robust are the ideas developed above to the possibility of multihoming? Let us discuss this question using again the model developed by Armstrong (2006) but assuming that one side, say side 1, still single-homes while the other side, therefore side 2, wants to join both platforms. This multi-homing behavior dramatically changes the competition between platforms. As far as side 2 is concerned, the agents make their choice to join each platform separately. Given that a side-2 consumer can join both platforms, there is no more direct competition to attract consumers from this side. ${ }^{\text {[U] }}$

\footnotetext{
${ }^{14}$ In Armstrong's analysis, multi-homing eliminates all direct competition because marginal consumers of one platform would join the other platform in any case. A more balanced view emerges when multi-homing is driven by disparity in individuals' valuation of network externalities. Then some marginal consumers multi-home while others single-home so that there is still some direct competition but less than without multi-homing, and the qualitative conclusions are similar (see Doganoglu and Wright, 2006).
} 
This lack of competition has the immediate consequence of changing the bargaining power between the agents and the platform. Indeed, because each side- 1 user singlehomes, these users are a scarce resource for which each platform is ready to fight. And if any side- 2 agent wants to be connected to a specific agent from the other side, they have to join the platform this specific agent has joined. In this case, the platforms act as competitive bottlenecks. Consequently, they will raise their price on side 2, leading to too few of these agents on their networks. As far as the price on side 1 is concerned, it is more ambiguous. On the one hand, the value destroyed for a competitor by attracting some of its side- 1 customers does not transform into a competitive edge on side 2 since there is no direct competition anymore. On the other hand, the value generated is larger because of larger market size under multi-homing. Note that the impact of multi-homing on the price can be understood by using Equation (1) derived in Section 2.3.1. Indeed, as far as side-2 agents are concerned, there is no more value destroyed for the competitor if the marginal consumer attracted multi-homes. Therefore the last term vanishes and the price goes up. Regarding side- 1 , the last term also vanishes, because a multi-homing side- 2 agent cares only about the incremental value of the platform on side- 1 instead of the differential value between the two platforms. But the first term increases because multi-homing raises side- 2 participation. Therefore, the single-homing side can benefit or lose from the introduction of multi-homing on the other side (see Belleflamme and Peitz, 2019). This issue of multi-homing vs. single homing is thus crucial to understanding properly how platform competition takes place.

The original contribution of Rochet and Tirole (2003) provides an alternative set-up in the case of transaction platforms, that is when platforms control the transaction between sides and thus can set fees per transaction. ${ }^{[3}$ They consider a situation in which some platforms intermediate trades between buyers and sellers but, in contrast to Armstrong (2006), the price paid by each agent is only a transaction fee, and not a subscription fee. Buyers have preferences for platforms but they may decide to join both if their preferences are weak. This means that some buyers, those with strong preferences, will single-home as in Armstrong (2006) whereas others, those with weak preference, will multi-home. On the sellers' side, they must decide whether they are ready to accept trades on both platforms. If they are, the platform on which the trade is made is determined by the buyer. If a seller chooses to join one platform only, the one that sets the lowest transaction fee, it limits the number of potential trades (because some consumers will refuse to trade on this platform) but increases the average revenue as the seller will realize all its trades on the cheapest platform. As in Armstrong (2006), prices depend on the cost, on the externality generated on the other side but also on the elasticity of demand. As far as buyers are concerned, this elasticity depends on the price and on the consumer's preference toward one platform or the other. The specificity lies in the way platforms set their prices

\footnotetext{
${ }^{15}$ See Reisinger (2014) who studies the combination of transaction fees and subscription fees in a model with heterogeneous trading behavior of agent
} 
for sellers. Let us assume that a seller has already joined platform A. This means that this seller is able to trade with all the buyers on this platform. If the seller also joins platform $\mathrm{B}$, this increases the number of potential trades, because some single-homing buyers join platform $B$ only. The more buyers are loyal to platform $B$, the more it pays for a seller to join this platform. Therefore, the price this platform will be able to charge for this seller increases in relation to the percentage of loyal (or single-homing) buyers. This contribution highlights the idea that platform prices targeted at multi-homers are set in proportion to the incremental value generated by the platform. In media markets, or in the context where some advertisers constitute one side of the market, this value is the gain attached to increased exposure, in particular to new consumers (see Anderson et al., 2017). Similarly, the incremental value of joining several social networks may lie in the ability to reach more friends, different content focus and privacy concerns. This incremental pricing principle is at play in most models of platform competition and explains why the issue of single-homing vs. multi-homing must be accounted for.

\subsection{Remarks on coordination and beliefs}

Coordination between users, both at the level of consumers and of firms, is a key aspect of platform competition. As this coordination of action is driven by the beliefs agents can hold, the way beliefs are formed and modeled plays a crucial role in the analysis of platform competition.

Let us first start by discussing the role of beliefs on market outcomes in the case of an emerging firm proposing a network good. The benefits derived by any user from a network good depends on the characteristics of the good but also the number of other users. When evaluating this latter network benefits, a potential user must form some anticipations on the behavior of other users. In this static setting, the natural assumption is to assume fulfilled expectations. If potential users only differ in standalone value for the good, some users are more eager to buy the good because this value is high whereas others will buy the good only if they believe that enough people will do so. When network effects are the dominant element driving the consumers' decision, there may exist several stable demand configurations, with various levels of participation. A low level of participation reduces the value of the good which makes it rational for a large part of consumers not to buy, while a large level of participation induces more consumers to buy. Of course, prices matter. Indeed, suppose that the price is above the highest standalone value but below the maximal value of network effects (obtained when all consumers buy the good). When the market share is zero, there is not enough benefit for the first agent to join the network. Conversely, when the market share is one, the total benefit (standalone value plus the total externality) is more than enough to induce the last consumer to join if all the others have already joined the network. So we may end up with a final situation in which there is no user, but it is also possible that all consumers adopt the network good. 
And also potentially an intermediate equilibrium where a subset of the most eager users buy the good. ${ }^{\square 6}$

When firms compete with network effects, the market outcome is again shaped by consumers' beliefs. But the issues are even more complex than above as one must consider not only participation in the market but also how this participation is shared across platforms. The situation is, therefore, one of competition with externality. Two main questions arise in this context, the first related to coordination and the second to information.

First, coordination issues arise when there are multiple equilibrium allocations of consumers across platforms and the way the equilibrium is selected affects the market dynamics. Focality or incumbency advantage is an illustration of this. In this case, consumers' expectations tend to advantage one platform over the others which may lead to excess inertia or excess momentum (see Farrell and Saloner, 1985). However, markets can coordinate in different ways. For instance, many authors assume away coordination failures by focusing on allocations that are optimal from consumers' perspective or by simply assuming that platforms can choose quantities on each side of the market (see Rochet and Tirole, 2006). Weyl (2010) and Weyl and White (2016) argue that platforms have enough pricing instruments to overcome the coordination problem. They define an equilibrium concept, insulated equilibrium, based on the idea that prices are designed in such a way that participation on one side is not affected (at the margin) by participation on the other side.

While solving coordination issues may favor economic efficiency, it may not benefit consumers because coordination failure may protect them against excessive use of market power. To illustrate this, consider a monopoly platform facing "unfavorable beliefs". Consumers will benefit if the platform must subsidize participation on one side to overcome the coordination issue. If instead consumers coordinate most efficiently, the platform can extract all the surplus from consumers by charging high prices on both sides because consumers expect others to participate. Regarding platform competition, it is important to realize that not only consumers' beliefs matter but also the interaction with firms' beliefs. Indeed the intensity of competition at a given period depends on firms' beliefs about which firms will be favored by consumers in the future. In Halaburda et al. (2020), it is shown that this generates multiple equilibria when firms are forward-looking, one in which the incumbent is never displaced and would fight very aggressively to regain market leadership if it were to lose it. Also, entry may be impeded if it takes very long to change consumers' beliefs.

The second issue relates to consumers' information and demand elasticity. This was illustrated by the work of Jullien and Pavan (2018) on consumers' beliefs and information. As consumers must anticipate participation on the other side, the equilibrium depends on how these expectations are formed. The most prominent view (Caillaud and Jullien, 2003, Rochet and Tirole, 2003) is that when prices change, consumers adjust their beliefs

\footnotetext{
${ }^{16}$ See Belleflamme and Peitz (2015), Chapter 20, for more details on this.
} 
and correctly anticipate the participation on the other side (referred to as rational expectations). This view emphasizes the role of feedback effects between sides and may prevail if demand adjusts fast. However, an alternative view is that consumers hold fixed beliefs about the other side's participation that do not vary when prices change (although beliefs are assumed to be correct at the equilibrium market price). ${ }^{\square}$ Because this approach assumes less internalization of network externalities by consumers, it leads to less elastic demands and thus to higher equilibrium prices (see Hagiu and Halaburda, 2014). The same remark holds for the Cournot assumption that firms choose volumes on each side and volumes are correctly anticipated by consumers.

Users' anticipations are crucial when network effects are present, both in one-sided and two-sided contexts. This implies that first it is hard to predict which platforms consumers will join when they have the choice and second that platforms have incentives to influence user's belief (see the discussion of Jullien and Pavan, 2018). Therefore, the conclusions that can be drawn from current models of platform competition should be taken with caution when applied to actual markets.

\section{Competition Policy}

At the general level, the difficulty for competition policy comes from the lack of a proper competitive benchmark for activities involving large demand externalities, such as those induced by network effects. ${ }^{\square]}$ With network externalities, the link between competition and consumer surplus is more complex and subtle than in markets without network effects, as some user prices may fall and network externalities may be better internalized with less competition, increasing consumer welfare.

The contributions discussed below help framing and understanding platform conducts. But before we discuss these contributions, three points are worth noticing. First dynamic competition, innovation or behavioral factors affecting platforms are currently insufficiently understood. Second, efficiencies arising from a particular conduct will be considered by authorities only if deemed necessary and theory papers do not always consider alternative ways to achieve efficiencies. Third, while platform activities create new opportunities for abusive conduct, the main question is often not so much whether a powerful platform has the ability to do so, but rather whether it has the incentives to do so.

In what follows, we focus on what is new about platforms that differs from traditional markets. Of course, this does not mean that traditional analysis of anti-competitive conducts never applies to platforms; it often does. After discussing the market power

\footnotetext{
${ }^{17}$ See Hurkens and Lopez (2014) who study the role of expectations in the context of mobile telephony and show that such passive expectations provide better modeling of actual behaviors.

${ }^{18}$ For general perspective, see reports by Argentesi et al. (2019), Crémer et al. (2019), Furman et al. (2019), and Scott-Morton (2019) among others.
} 
of platforms, we will examine the following issues: exclusionary pricing and predation, exclusivity, bundling, vertical foreclosure, collusion, and merger policy. ${ }^{10}$

\subsection{Market Power}

A well-known difficulty in identifying market power is that platforms may implement strong price skewness, with some sides being charged low or zero prices and others being charged relatively high prices (see Sections 2.2 .2 and 2.3.1). ${ }^{20}$ Thus, when looking at margins, the whole structure across all sides should be considered. ${ }^{\text {[T }}$

This is illustrated by the competitive bottleneck model discussed before. An adfinanced platform may generate little profit because it competes harshly to capture and retain consumers. However, based on the analysis of the competitive bottleneck, there should be no presumption that the outcome is efficient and that profit dissipation can free a platform from anti-trust scrutiny.

Indeed securing (on the merit) a large exclusive consumer base provides market power over advertisers. Exploitative conduct on the multi-homing side may then lead to inefficient participation levels. Moreover exclusionary conduct, e.g. exclusive agreements, switching costs or foreclosure, may distort competition, denying consumers some valuable options.

A consequence of the blurred relationship between margins and market power is that the evaluation of platform market power may weight relatively more non-price evidence compared to the case of one-sided competition.

A major issue is that platforms are typically offering multiple (one-sided or two-sided) services. This is because once connected to a user, a platform can leverage economies of scope to expand its activities and many aim at building a one-stop ecosystem for consumers. ${ }^{[2}$ Given that platforms with very different profiles may compete, the concept of a single product market definition or several independent markets will not fit the situation of platforms, except in rare occasions. Indeed platform competition involves a nexus of markets, related through heterogenous envelopment strategies (See Eisenmann et al., 2011). ${ }^{[23}$ Dealing which such cases will require recognizing the interlocking between mar-

\footnotetext{
${ }^{19}$ We leave aside price-parity clauses and the agency model. See Edelman and Wright (2015), Boik and Corts (2016), Johnson (2017) or Wang and Wright (2020).

${ }^{20}$ See Affeldt, Filistrucchi and Klein (2013) for the measurement of incentives to raise margins.

${ }^{21}$ For transaction platforms with price-insensitive transactions, it is useful to decompose fees into the average total fee per transaction and the spread on fees between sides. Two-sidedness is then reflected in the spread while as shown by Rochet and Tirole (2006), a one-sided logic of monopoly price distortion applies to the total fee (see Aymanns, Dewatripont and Roukny, 2019, for recent applications).

${ }^{22}$ Estimating demands in this context is more complex than in more standard industries but ongoing research is developing technical tools to do so (see, for instance, Argentesi and Filistrucchi, 2007).

${ }^{23}$ Envelopment refers to the strategy of a platform leveraging economies of scope, data and customer relationship to expand its offering to other platform services.
} 
kets and the need to have a global cross-market analysis.

When it comes to defining market and establishing market power, there is no onefit-all solution. The policy discussion made a distinction between transaction platformsthat intermediate direct economic transactions-and non-transaction platforms-such as social networks. ${ }^{\text {W4 }}$ This is relevant insofar as the ability to identify/measure transactions provides platforms with richer tariff possibilities and better ability to internalize network effects. ${ }^{53}$ However, as discussed in Niels (2019), the distinction is often blurred in practice and the framework of cross-side externalities applies to both types of platform. ${ }^{26}$

In the context of this nexus of markets, a few points emerging from the existing economic literature are worth highlighting. A first obvious point, expressed by the US Supreme Court in the Amex case, ${ }^{27}$ is that any evaluation of a competition case involving a multi-sided platform should consider effects on all sides. Indeed cross-side externalities imply that actions affecting one side affect also the other side. A second point emphasized in some policy discussions (see Niels, 2019) is that the market definition chosen may depend on the conduct in question. ${ }^{18}$ Moreover it may focus less on demand substitutability than for traditional markets, putting more emphasis on supply substitutability and potential competition. Identifying actual and potential competitors-more generally firms constraining or affected by the platform's activity- will require considering that differentiated business models can compete on some or all activities (free/paid, one-sided/two-sided...) A third point is that behavioral factors matter. This includes for instance single-homing/multi-homing behavior, as discussed in Section 2.3.2, or statusquo bias. The literature also points that, when coordination failure may occur, consumer beliefs are an important determinant of market power. Not only these factors affect competition in the market but they also affect competition for the market. In particular they determine the extent of incumbency advantage (Biglaiser and Crémer, 2020). Identifying the existence of a "focal" platform or of consumer inertia may help understanding the source of market power.

A more technical issue is the test to delineate relevant markets. ${ }^{[9}$ Textbook market

\footnotetext{
${ }^{24}$ See Filitruchi et al. (2014), Niels (2019) and the Supreme Court decision in Ohio v. American Express Co., 585 U.S..

${ }^{25}$ The fact that rich tariffs can help resolve coordination problems is emphasized in the notion of insulating tariff developed by Weyl (2010) and Weyl and White (2016).

${ }^{26}$ The literature also identifies "attention platforms" as the special case of platforms competing for consumers attention and monetizing attention through advertising (Prat and Valletti, 2019). This provides a framework where platforms are gatekeepers for entry (through ads) in product markets, that may allow better understanding of potential theory of harm in cases of this nature.

${ }^{27}$ Ohio v. American Express Co., 585 U.S, 2018.

${ }^{28}$ To quote M. Monti acting as former Competition Commissioner "market definitions only make sense in the context in which questions are posed", https://ec.europa.eu/commission/presscorner/detail/en/SPEECH_01_439.

${ }^{29}$ The interested reader may consult the excellent report on market definition and market power by
} 
definition is guided, at least conceptually, by the SSNIP test. Provided that a well defined two-sided market is identified, this approach can be adapted to account for feedback effects between different sides of the market and there are several ways to achieve that, depending on the assumed coordination between prices on the two sides of the market (see the discussion in Evans and Noel, 2008, Filistruchhi, 2018, Franck and Peitz, 2019, or Niels, 2019).

A difficulty emerges if the service is free on some side of the market. ${ }^{\text {Ba }}$ As we have seen, this arises when the platform would be willing to subsidize participation to generate externalities but cannot because this is not sustainable. Although not a conceptual issue, free goods raise the level of complexity of the analysis. First, it reveals a constraint on pricing that has ambiguous effects on the extent of barriers to entry. Second, the locus of competition for consumers shifts from prices (that are easily observable) to non-price competition, in particular quality of service and privacy policy for digital platforms. In this case, it is conceivable to use a SSNDQ test (small but significant non-transitory decrease in quality). ${ }^{[3]}$ Quality of service is however complex to measure and to our knowledge, there is currently no well-established measure of quality. ${ }^{[2]}$

We conclude this section by reminding that even if one identifies market power, the question of the exercise of market power remains. Market power is a capacity, not a behavior. In most industries, the capacity to exercise market power implies exploitation of this market power as it is the sole source of profit. But platforms have multiple sources of revenue and may choose not to exploit their market power if the resulting large participation induces large profit on the other side, or at least if it is larger than the foregone profit.

\subsection{Exclusionary pricing}

From the early development of models of two-sided markets, it has been claimed that below-cost pricing on one side should not raise a presumption of a predatory attempt to exclude competitors, as below-cost pricing may result from pro-competitive considerations. Notice that the issue is not new or specific to platforms as it arises in economic activities involving product complementarity, e.g. transportation, distribution or software. The literature has shown that competition may exacerbate price skewness as firms compete to attract the most valuable consumers. In what follows, we first review some

\footnotetext{
Franck and Peitz (2019).

${ }^{30}$ See Gans (2019) for a discussion of specific issues with zero price.

${ }^{31}$ We thank a referee for pointing that to us as well as the fact that the conceptual framework of SSNDQ was used by the European Commission in Case AT.40099, Google Android.

${ }^{32}$ OECD Directorate for Financial and Enterprise Affairs Competition Committee,'The Role and Measurement of Quality in Competition Analysis'(2013) DAF/COMP(2013)17.
} 
relevant material from one-period models and then discuss the case of long-horizon and forward-looking firms.

Contributions focusing on one-period models of price competition have shown that whether or not below-cost pricing results in socially sub-optimal entry depends on the precise context. A corollary of the analysis of Caillaud and Jullien (2003) is that when there is incumbency advantage and strong network externalities, below-cost pricing may help an incumbent preserving its market from efficient entry. ${ }^{33}$ However, the protective role of below-cost pricing is countervailed by the flexibility that divide-and-conquer strategies provide to new entrants in building market shares. Faced with a more efficient entrant, the incumbent's defensive strategy subsidizing one side is vulnerable to entry strategy that subsidizes the other side. The cost of protecting its position on all sides of the market may be so high that the monopoly may prefer accommodating entry. By contrast with the case of pure intermediation services (Caillaud and Jullien, 2001 and 2003), Jullien (2011) concludes in a sequential pricing game with incumbency advantage that when network externalities are not too large, there may be either excessive entry or excessive market fragmentation. In this fragmented case, potential network externality benefits are wasted. A conclusion of excessive entry accommodation is also reached by Vasconcelos (2015) in a model where an installed base of locked-in consumers on both sides of the market provides incumbency advantage. By contrast, in a sequential pricing game with fixed costs, Amelio et al. (2020) establishes the existence of consumer harmful entry deterrence for some intermediate range of entry cost. Overall, while establishing the possibility of inefficient barriers to entry, the literature is not conclusive.

To our knowledge there are few contributions with a long-horizon perspective. Interpreting the model of Halaburda et al. (2020) (discussed in Section 2.2.I) as a post-entry game shows that incumbency advantage and strong network externalities may induce barriers to entry when firms are forward-looking. This article highlights the importance of consumer beliefs and self-fulfilling prophecies, but also the belief of market players as they determine their willingness to sacrifice profit. This suggests that authorities should devote special attention to dis/information strategies, communication and marketing. Indeed convincing the market that a competitor will fail may suffice to induce the failure.

Standard theories of predation apply to platforms as well as to any other firm (see Bolton et al., 1999, for a review and discussion). As building network externalities and reaching a critical mass may be costly and long, an entrant would need to secure enough financial support to sustain the loss incurred in the first stage of entry. Theories of financial predation under asymmetric information (see Bolton and Scharfstein, 1990) may

\footnotetext{
${ }^{33}$ Along this line, Karlinger and Motta (2012) shows that when a critical size is necessary to generate network externalities, an incumbent may exploit consumers' lack of coordination and preserve its monopoly position with targeted offers.
} 
thus be relevant. A platform could also credibly develop a reputation of aggressiveness toward entrants or try to manipulate market signals. ${ }^{1.4}$

One debated issue is the relevant test for predation. The actual approach to predation relies on a combination of sacrifice test and recoupment test. ${ }^{[5]}$ Following the AreedaTurner rule, the most common way to establish a sacrifice is to compare actual prices with average costs or with average variable costs (as a proxy for marginal costs). As for market power, price-skewness challenges this approach. A test at the two-sided market level is possible but may generate false negatives. An alternative is to conduct a test on each side, building on the pricing formulas discussed in the Section 2.3.7. Indeed prices follow a standard markup formula but where the costs must be adjusted for any opportunity cost. Hence, the relevant "marginal cost" on one side is equal to the cost net of any revenue that a customer on one side allows the platform to generate on the other side. Defining the relevant marginal cost this way would provide a partial competitive benchmark for efficient pricing on each side. Based on this insight, Berhinger and Filistrucchi (2015) propose and discuss an extension of the Areeda-Turner rule that has two novel features. First, given that the market involves two sides and two prices, there are two tests, one for each side. Second, each test accounts for the margin on the other side of the market and cross-side demand externalities. ${ }^{\text {[6] }}$

\subsection{Exclusivity}

Armstrong and Wright (2007) were the first to point to the possibility that two-sided platforms use exclusive dealing as a way to prevent multi-homing. ${ }^{13}$ Preventing multihoming is unilaterally profitable because multi-homing on one side of the market reduces the revenue that a platform can obtain on the other side of the market. They analyze several models and show that the possibility of offering exclusive contracts destabilizes equilibria where agents multi-home on one side. In a model of competitive bottleneck -where profit is dissipated through competition for single-homers- they show that by offering exclusive contracts on the multi-homing side, one platform can monopolize the market. The resulting equilibrium then involves tipping and lower consumer surplus than without exclusive contracts.

Carroni et al. (2019) further develop the analysis of exclusivity by noticing that exclusivity of an agent generating large externality (a superstar) helps convincing other agents on the same side (say sellers) to stop multi-homing and join the platform exclusively.

\footnotetext{
${ }^{34}$ Predatory pricing in the presence of learning by doing (Cabral and Riordan, 1994, 1997) may be relevant in the presence of dynamic network effects (Hagiu and Wright, 2020).

${ }^{35}$ See Kaplow (2018). There are differences between various jurisdictions. For instance the US approach insists more on the need of demonstrating recoupment than EU. Demonstration of intent matters also.

${ }^{36} \mathrm{~A}$ difficulty is that this benchmark depends on the platform's behavior on the other side of the market.

${ }^{37}$ There are of course other motives for exclusivity not specific to platforms that we do not explore, such as protecting specific investments or preventing free riding.
} 
This is because, exclusivity of the superstar shifts demand on the other side of the market (consumers) toward the superstar's platform. Multi-homing then becomes less attractive for sellers (the incremental value of the competing platform decreases) and more sellers single-home along the superstar, which induces a virtuous participation circle through the two-sided feedback loop. However, gaining exclusivity requires costly compensation of the superstar for lost interactions on the competing platform. Carroni et al. (2019) conclude that exclusivity will emerge if the intensity of competition is strong on the consumer side and that this may benefit small sellers and consumers because seller participation increases and larger network externalities are generated. Thus, even if exclusivity may lead to tipping, it will not necessarily reduce social welfare.

In these two contributions, exclusivity is a tool to gain competitive hedge at the cost of reduced overall externalities between sides. Along this line, empirical investigation of the video game industry between 2000 and 2005 by Lee (2013) has shown that exclusivity of software significantly reduced demand for both hardware and software.

Another concern with exclusive contracts is that they may protect a dominant position. In particular, it is well known that exclusive dealing may be used to raise barriers to entry when there are increasing returns to scale within the market (see Rasmusen et al., 1991, and Segal and Whinston, 2000) or across markets (Bernheim and Whinston, 1998). Given the similarity between network externalities and returns to scale, the same should occur in platform competition. Doganoglu and Wright (2010) confirm this insight. They assume that an incumbent can make introductory offers to a subpopulation of consumers before price competition with an entrant. Absent exclusive dealing, introductory offers are inefficient at protecting the incumbent against an efficient entrant because targets of introductory offers can multi-home afterward and will do so if other consumers buy only the entrant's product. Exclusive introductory offers allow the incumbent to secure the exclusive participation of a critical mass of users and to gain a competitive advantage as other consumers seek the network externality induced by the exclusive consumers. In this case all users buy the incumbent platform's product and the entrant must contend with inducing multi-homing with a low price for the incremental benefit of higher quality. As a result, entry is impeded and occurs at a suboptimal scale.

As pointed out by Evans (2013), the other side of the coin is that exclusivity may help an entrant improving coordination on its efficient platform. ${ }^{\text {B8 }}$ A recent study by Markovich and Yehezkel (2019) further investigates this question in the presence of a user-group, i.e., an institution coordinating the choices of a group of users (such as a cooperative, an investment fund or a bank adopting a credit card). In their model, firms bid for the user-group before competing for other users. But due to an incumbency advantage, a new entrant faces difficulty in coordinating the consumers on its platform. Introductory offers to the user-group facilitate entry if participation of this group induces a bandwagon effect that attracts other non-coordinated users. However, when the group

\footnotetext{
${ }^{38}$ Lee (2013) suggests that this was the case for the video game industry.
} 
chooses to multi-home (hence under non-exclusivity), the bandwagon effect vanishes and it is difficult for the entrant to overcome the incumbency advantage. By contrast, gaining the exclusive participation of the user-group may allow the entrant to win competition for the rest of the market. However, while exclusive offers facilitate entry, barriers to entry still exist as the incumbent may subsidize the user-group to preserve its monopoly position.

One reading of the literature on exclusivity is that it can help a platform monopolizing a market or protecting its dominant position. To this respect exclusivity by dominant platforms may deserve special scrutiny when network effects are large. Unlike incumbents, new entrants in platform markets need to overcome coordination issues due to network externalities, which is facilitated by exclusive offers. This suggests an asymmetric treatment of exclusivity, although one should be aware of the risk of excessive entry.

When there is competition on the market between non-dominant platforms, exclusivity may be a way for a competitive platform to improve its position rather than to exclude a competitor. In this context, as shown by Belleflamme and Peitz (2019), multi-homing (and its counterpart exclusivity) may benefit either side of the market and it is difficult to say whether it improves or harms welfare.

\subsection{Bundling}

Bundling is a common and well-known phenomenon on the internet. The prominence of bundling in information services relates in part to the fact that these services incur very small variable costs. ${ }^{39}$ As platforms benefit from economies of scale and economies of scope, there is very little cost in using a platform to offer a service to all the population rather than a targeted sub-population. In this context, it may be more profitable to offer all the services in a bundle with a single total price, rather than setting a price per service and letting customers choose which services they want. Traditional economic analysis identifies price discrimination and exclusion as two motives for bundling (see Fumagalli and Motta, 2018). This applies to platforms but there are also some specificities that we now discuss.

We start with a contribution related to discrimination, in that bundling allows platforms to change the prices faced by different types of users. Amelio and Jullien (2012) point to the fact that a motive for bundling is to raise the value for consumers on a free side of the market. In their model, adding an additional service to a free service is akin to setting a negative price when a monetary subsidy to consumers is not feasible for practical reasons (either technical or because of consumers' opportunism). This is thus a way to boost demand on one side and it is optimal when the increased participation raises the network externality on the other side of the market, hence the revenue. Amelio and

\footnotetext{
${ }^{39}$ See Bakos, Y. and E. Brynjolfsson (1999).
} 
Jullien (2012) identify conditions for a monopoly and a symmetric duopoly to set a zero price on one side and investigate the consequences of allowing a platform to bundle the service with another good on one side. They show that bundling by a monopoly platform is pro-competitive as consumers on the free side benefit from higher utility of the bundle while consumers on the other side benefit from higher externality. In a competitive context, the analysis of bundling is more complex because attracting a pay consumer becomes costlier to the platform, as the two-sided network feedback raises the loss on the subsidized side. Bundling is thus a costly way to raise demand on both sides and the higher cost results in less pricing aggressiveness on the pay side. Bundling by two competing platforms reduces total consumer welfare because the demand-shifting effects cancel each other while prices increase on the pay side. When only one platform can do it, bundling may not be profitable if the competing platform is too aggressive in preserving its market share, and it may hurt or benefit the competing platforms due to competition softening. Their general conclusion is that bundling "raises total welfare [in] situations with large externalities and strong competition".

Choi and Jeon (2020) further clarified the interaction between bundling and non-negative price constraint by considering a monopoly that ties its good with in a free, ad-financed service. Their key point is that because the tying service is free, a competitor already constrained by non-negativity of prices cannot react aggressively. According to the same logic as Amelio and Jullien (2012), the monopoly is able to sacrifice profit from the monopoly good to capture the advertising revenue of the free service. This provides the monopoly with an advantage allowing it to win competition to sell the ad-financed service when faced with a more efficient competitor.

While the previous analysis of bundling focused on independent goods, Choi (2010) highlights an exclusionary motive for tying a two-sided service with a monopoly product that is essential to the service-e.g. a media-player with the operating system. In this context, a well-known argument from the Chicago School is that a monopoly has no incentive to exclude rivals in the complementary segment because it can reap all profit through the price of the monopoly product. Choi (2010) argues that this logic does not apply if the complementary segment is two-sided and only one side buys the monopoly product. ${ }^{\text {ta }}$ The intuition is that the monopoly cannot capture the surplus created on the complementary segment for the side not buying the monopoly product. In Choi's model, the complementary service, proposed by the monopoly and a competing independent platform, allows content producers to access consumers. Absent tying, some consumers and some producers multi-home. Following the "incremental pricing principle", the presence of multi-homing consumers reduces the price that can be charged to multi-homing producers and the total profit of the platform. Tying the service is a way for the monopoly to break this logic by forcing all consumers to have the firm 's two-sided service. This helps convincing producers to single-home on the monopoly two-sided service. By reducing

\footnotetext{
${ }^{40}$ The analysis had some shortcoming corrected in Choi, Jullien and Lefouili (2017).
} 
the volume of content on the independent platform, this induces also more consumers to single-home, allowing the firm to raise the price to producers. While the paper shows a rationale for exclusionary bundling, it also concludes that absent distributive concerns and long-term considerations, bundling is socially desirable when it is profitable, as it gives consumers access to more content.

De Cornière and Taylor (2019) analyze pure bundling by powerful complementors of a platform. They consider a platform and some sellers of ad-financed complementary goods that can be provided by the platform to its consumers (e.g. mobile applications and smartphones). Sellers negotiate a profit-sharing contract to access the platform. In this context, they assume that one seller owns two applications, the first having no substitute and the second having substitutes offered by other sellers. The seller is powerful in the sense that consumer participation to the platform is drastically reduced if the first application is not available on the platform. They show that bundling its two applications allows the powerful seller to obtain better access conditions to the platform. This occurs because the competing seller of the second application becomes less aggressive. Indeed with independent negotiations for each applications, the size of the platform (hence the ad revenue from the second application) is not affected by the identity of the provider of the second application, which puts all sellers on equal footing. But bundling forces a single negotiation where the bundle competes with the second applications of other providers. The size of the platform is reduced if the powerful seller looses this competition because the first application is not available, which reduces also the ad-revenue of a winning independent provider compared to the unbundled case. ${ }^{-17}$ In this argument, bundling shifts profit from the platform to the monopoly application seller.

Disentangling pro and anti-competitive effects of bundling in platform competition is a challenging task. The new insights of the economic literature on platforms are twofold. On one hand, it points to circumstances where bundling raises efficiency by improving coordination of consumers. Arguing that this is the case will require demonstrating significant coordination failures and the necessity of bundling. On the other hand, it also shows that the practice raises new concerns that are specific to markets with platforms and that it should be the object of special scrutiny to prevent anti-competitive leverage of market power across markets. The literature pointed that the lack of price competition in ad-financed activity creates opportunities for such leverage. Participation externality across products may create other leverage opportunities.

\subsection{Vertical integration and vertical foreclosure}

Vertical integration is quite common for platforms which provide some complementary services in-house and rely on third parties for others. Vertical integration by platforms may have several efficiency motivations. In particular, as in any vertical supply chain, it

\footnotetext{
${ }^{41}$ The argument implicitly assumes limited space for applications on the platform.
} 
may raise volumes by eliminating "double marginalization". Moreover, it may facilitate investment and foster transfer of knowledge to the integrated branch. In the case of platforms, it has some additional benefits because it leads to better internalization of network externalities. For instance, direct sales by Amazon guarantee consumers a minimal and reliable supply of good-quality products while the marketplace raises the value of the platform by increasing diversity and the number of products.

By integrating some supply from side-2, a platform can credibly convince side- 1 consumers that they will be able to trade on the platform. This may help platforms to overcome the "chicken \& egg" problem when platforms face unfavorable consumer beliefs. This issue is discussed by Hagiu and Spulber (2013) in the context of a platform intermediating trade between content suppliers and buyers. As we have seen when buyers and sellers are potentially interested but skeptical about the success of a platform, this platform must develop a costly subsidization strategy through divide-and-conquer strategies. Then it may offer some integrated content to appear more attractive and reduce the subsidization cost. Assuling that integrated content boosts buyers' participation but impedes sellers' profit per buyer, Hagiu and Spulber (2013) show that offering integrated content is profitable whenever the platform subsidizes buyer's participation and generates profit on the sellers' side. The reverse holds if the platform subsidizes sellers' participation, as adding integrated content would raise the direct subsidy required to attract sellers. An intuitive conclusion they derive is that when buyers are single-homing, competition for buyers leads to a larger provision of integrated content. Insofar as the chicken \& egg problem concerns non-established platforms, this analysis should only apply to non-dominant platforms.

While vertical integration in complementary services by platforms may improve coordination, it also raises the issue of the foreclosure of competing third-party suppliers of complementary services. To illustrate this, Miao (2009) considers a monopoly seller of a platform good vertically integrated in a competitive complementary segment providing applications that allow third parties to interact with platform members. If the platform could charge third parties directly for accessing its customers, it would benefit from having a competitive complementary segment as this would maximize the value of its own service on both sides of the market. However, if the sole sources of revenue are the revenues from the sales of the platform good and the sales of the complementary application, the platform may have an incentive to monopolize the complementary segment by making its platform incompatible with other suppliers of the application. The reason is that competition on the complementary segment dissipates profit to the benefit of third parties. ${ }^{.2}$ Incompatibility with non-integrated complementary applications then allows the platform to monopolize the complementary segment and extract some rent

\footnotetext{
42 This assumes that the monopoly i) cannot extract third-parties rent by charging consumers for interacting with them (as may be the case with a monetary exchange between sides) and ii) cannot charge competitors a variable fee for compatibility.
} 
from third parties. This can be achieved by denying access to complementors but also by degrading interoperability or software integration, which would prevent level playing field competition.

De Cornière and Taylor (2014) provide a similar argument in the case of a search engine, based on the issue of appropriation of advertising revenue. They consider a search engine that guides the choice of consumers between several content publishers. Both the search engine and the publishers are solely ad-financed. In this context, the best choice of publisher for the consumer depends on the match quality of content and the nuisance from advertising that consumers will have to bear. When the search engine vertically integrates with a publisher, it tends to bias the search result in favor of this subsidiary to benefit from its advertising revenue. ${ }^{33}$ However, they show that there are two countervailing effects. First, as the total advertising revenue per consumer includes advertising revenue from both the search engine and the subsidiary publisher, the integrated firm has more incentives to boost total demand by providing high-quality advices for consumers. Second, the subsidiary internalizes the fact that higher utility from its content benefits the search engine and reduces its volume of advertising. Consequently, the effect of vertical integration on total welfare is ambiguous.

Due to the nature of their activity, platforms have many opportunities and ways to foreclose. The issue is therefore worthy of scrutiny by anti-trust authorities. It is particularly acute when foreclosure shifts third-party revenues which cannot be appropriated otherwise - such as advertising revenue or innovation rents - toward the platform's affiliate. However, as already mentioned, a platform may have the ability but not the incentives to foreclose. Here, the platform faces a trade-off between maximizing its longrun value, which requires a consumer-value orientation aimed at improving consumers' loyalty, and generating short-run profits through its subsidiary.

\subsection{Collusion}

Despite the existence of several cases of collusion between two-sided platforms, in particular in the media industry, platforms, collusion may occur on all prices but sometime only on prices on one side. For instance, some cases involved newspapers colluding on cover prices but still com-

\footnotetext{
${ }^{43}$ This reasoning assumes that the search engine cannot charge a listing fee to other publishers (results are organic).

${ }^{44}$ For example Citizen Publishing Co. vs. United States, 394 U.S. 131 (1969) for daily newspapers. Ruhmer (2011) mentions several German cases in TV or newspapers markets. Lefouili and Pinho (2018) mention cases involving newspapers in Venezuela (1996), Brazil (2005), Croatia (2010), Hungaria (2014) and Montenegro (2014). Non-media cases are COMP/E-2/37.784 (2002) involving auction houses, and AdC Décision $\mathrm{n}^{\circ} 19-\mathrm{D}-25$ (2019) on the market for restaurant vouchers.
} 
peting on the advertising side. ${ }^{\text {Th }}$ Thus, understanding collusion requires examining both possibilities. The key question is to know how platforms achieve collusion in the two cases and what are the resulting implications for consumers on the two sides. From the analysis of competitive and monopoly pricing, we know that a monopoly would not always set prices higher than competitive prices on both sides of the market. Following this insight, Dewenter et al. (2011) argue that colluding on one side may reduce prices on the other side, in which case collusion may benefit some users. An extensive treatment of this question in the Armstrong model is made by Lefouili and Pinho (2020). They first show that when all consumers single-home, the highest sustainable collusive profit is achieved with supra-competitive prices for both sides of the market if platforms are sufficiently differentiated on each side. If in addition sides differ in the substitutability between platforms, the result doesn't hold and the price may decrease on the side with the least differentiation. But the collusive price may be below competitive level on a side where differentiation is small (relative to network externalities). Things are even more complex when either some consumers multi-home or collusion occurs on one side only.

To see that, suppose first that users multi-home on one side and single-home on the other side. One may think of sellers being active on several platforms while consumers focus only on one, or advertisers buying space in several newspapers while consumers read only one newspaper. Recall that in this case, platforms compete to attract the singlehoming side (the consumers) and charge the other side to access them. As the populations of consumers on each platform are distinct, each platform charges a "monopoly" price for access to its consumers. Hence, absent collusion, multi-homers already face monopoly prices (for given demand on the other side). As a consequence, collusion has no direct effect on this side, unless it affects consumer participation. By contrast, collusion would raise prices on the single-homing side.

Suppose now that all users single-home but collusion occurs only on one side. ${ }^{\text {teg }}$ Lefouili and Pinho (2020) show that there is a subtle relation between prices, that reflects the dual nature of consumers on platforms: the consumer is paying for the good but is also a source of revenue (an input) on the other side of the market. If the firms set the collusive price above the competitive level, then the margin for new sales generated on this side increases and this intensifies competition on the other (non-collusive) side, because attracting these consumers is a way to raise sales on the colluding side. Anticipating that, colluding firms may decide to reduce the collusive price below the competitive level in order to relax competition on the competitive side of the market. This occurs when the

\footnotetext{
${ }^{45}$ For instance CADE - Processo Administrativo no. 08012.002097/99-81. (2005) or CCA vs. daily newspaper publishers-UP/I 030-02/2008-01/072 (2010). Argentesi and Filistrucchi (2007) found empirical evidence of collusion restricted to cover prices in the Italian daily newspaper market between 1976 and2003. Rumher (2010) and Dewenter et al. (2011) mentions German cases involving collusion on the advertising side only.

${ }^{46}$ For instance, the prices may be set by different agents on both sides, only those on one side colluding while others set prices to maximize the short-run firm profit.
} 
externality generated by agents of the non-collusive side is large, such that competition is intense. By contrast, if agents on the non-collusive side generate a negative externality (say, advertisers generating a nuisance on readers), then all prices increase when collusion emerges.

To summarize, despite a general presumption is that collusion would lead to higher prices and lower consumer surplus, there may be situations where consumers on one side benefit from lower prices when firms collude. In particular, some consumers may gain when collusion only occurs on one side, whether it is on their side or the opposite. These general conclusions apply to tacit collusion as well as to cartels.

\subsection{Mergers}

In this section we first discuss horizontal mergers and work on vertical mergers not related to foreclosure.

Chandra and Collard Wexler (2009) were the first to point out that a merger between two-sided platforms needs not lead to high prices. They assume that readers of two newspapers are heterogenous and advertisers' value depends on the composition of the population reached. Lack of targeting along with uniform cover prices implies that the contribution of a marginal consumer to profit may be negative or positive. ${ }^{\text {TI }}$ If a price increase diverts to the other outlet consumers whose contribution to profit is negative, then a merged entity controlling both outlets may reduce the prices. That a merger may lead to lower prices on one side of the market when externalities are large is confirmed by Leonello (2010) and Cosnita-Langlais et al. (2016). Indeed, as already highlighted by the analysis of collusion, when the externality generated on the other side is large, it may be more profitable to raise revenue on this other side by boosting participation with lower prices than to extract more profit by raising prices. ${ }^{\text {t8 }}$

The effect of mergers is further investigated by Correia-da-Silva et al. (2019) using a Cournot model of platforms with single-homing. In this model, each platform sets a quantitative objective, in terms of the number of users it plans to have on each side. Prices on all platforms then adjust and consumers allocate across platforms until all platforms have met their quantitative objective. ${ }^{19}$ The Cournot model with homogenous platforms (i.e., platforms that every consumer would find equally attractive for equal network externality) implies that prices adjust to the level of the externality by each platform, so that consumers are indifferent. A merger concentrates agents on fewer platforms, raising

\footnotetext{
${ }^{47}$ It is negative if the price margin is negative and of larger magnitude than the marginal effect of the consumer participation to advertising revenue.

${ }^{48}$ Other conclusions from analysis of collusion do not extend in a straightforward manner to the analysis of mergers because the price structure under collusion is shaped by the incentives to reduce deviation profit.

${ }^{49}$ As discussed in their paper, the Cournot model should no be interpreted here as resulting from physical considerations, but as a behavioral equilibrium concept reflecting firms and consumers beliefs about the market and equilibrium play.
} 
participation on both sides of each platform and thus increasing the value of network effects. Higher network effects, combined with the standard effect of a Cournot merger on residual demand elasticity, tends to raise overall margins. When pre-merger margins are large relative to network externalities, all prices increase and consumer surplus declines on both sides. But when all margins are small and total network effects are large, the merger benefits all users due to a reduction of market fragmentation. ${ }^{\text {W }}$

The literature related to the impact of mergers in two-sided media markets is reviewed in Foros et al. (2015). In their seminal work on the two-sided approach to media markets, Anderson and Coate (2005) underline the disciplinary role of competition for consumers on the volume of advertising chosen by a media outlet. By relaxing competition, a merger results in more advertising and lower consumer surplus. However, this result is specific to the competitive bottleneck set-up and is reversed if most consumers multi-home (see Anderson et al., 2019). In this case, there is little competition for consumers and the traditional effect of a merger prevails on the advertising side: increased market power leads to high advertising prices and lower volume. Prat and Valletti (2019) also pointed that a merger between media platforms may foster preemptive advertising by incumbent producers, raising barriers to entry on advertised product markets.

An interesting feature that emerges with mergers of platforms is the possibility of a "see-saw" effect, namely that consumers on one side benefit from the merger while those on the other side are harmed. Correia-da-Silva et al. (2019) demonstrate that for intermediates levels of externalities, consumers on the highest-cost side (low margin) benefit while consumers on the other side are harmed. Intuitively consumers generating high externality (hence low-margin side) become more attractive when participation on the other side increases and thus should be the first to benefit from the merger when total network effects increase. Anderson and Peitz (2020) identify conditions for a see-saw effect of a free media merger, with decreasing consumer surplus and increasing advertiser surplus; ${ }^{5 \pi]}$ they show that this is less likely to occur with two-sided pricing. ${ }^{52}$

One main difficulty of merger analysis is that, unlike standard merger analysis, competing platforms may have different business models (as discussed in Section 2.3.1). Some may charge all sides while others charge only one side; some may rely on subscription while others rely on transaction fees. Moreover, platforms offer different bundles of goods and services. Standard models for merger analysis struggle to cope with such diversity. At the theoretical level, an interesting alternative to standard price-competition models explored by De Cornière and Taylor (2020) is to rely on so-called "utility competition" (Armstrong and Vickers, 2001), where firm do not compete in price but in total value offered to consumers. They show that this approach can accommodate many features, in particular different business models, and its flexibility could make it suitable for some

\footnotetext{
${ }^{50}$ For intermediate cases, the merger benefits only one side.

${ }^{51}$ This assumes no pass-on to consumers of lower advertising cost.

${ }^{52}$ See also Anderson et al. $(2012,2019)$ for the effect of consumer multi-homing or advertising congestion.
} 
case handlings. De Cornière and Taylor (2020) exploit this flexibility to discuss the effect of data on the intensity of competition. In the case of vertical integration by a firm using data as input, they show that integration affects the incentives of the upstream subsidiary to invest in data collection. ${ }^{63}$ Indeed, the vertically integrated firm may disinvest in data collection and reduce welfare if data is pro-competitive downstream. The reverse holds if data weakens competition downstream.

The literature on mergers of platform is still in its infancy, due to the difficulty of modeling multi-platform competition. But some lessons already emerge. ${ }^{54}$ First, a general presumption that prices increase on all sides following a merger does not hold for platforms. Consequently, it will be necessary to identify more precisely price effects in different contexts. Second, when some agents single-home on both sides, any merger involves some immediate efficiency gains due to larger network externalities in less fragmented markets. Hence, a merger evaluation should focus on prices adjusted for externalities rather than just prices. It can be the case that prices increase but consumer surplus increases due to larger network externalities. Third, as the merger affects different populations on each side, there may be conflicting interests of different groups of users (readers and advertisers, buyers and sellers, etc.). Balancing the interests of the various sides may be a difficult exercise and may require extending the analysis to the value chain outside the platform (for instance, advertisers are themselves intermediaries and, ultimately, we should care about producers and consumers using their services).

\section{Conclusion}

This article was motivated both by the debate related to the growing role of platforms in the economy and by the need to take stock of 20 years of research in economics on platform competition. The particularity of platforms - and therefore of competition between these platforms - comes in large part from the importance of network externalities. While in a mature industry involving network externalities, one may expect users to be quite homogenous in their expectations, many modern platforms are innovative intermediaries connecting heterogeneous users with heterogenous beliefs (consumers/firms, readers/advertisers, ...). This creates scope for price discrimination and complex pricing and non-price strategies. The question of the efficiency of the competitive process but also of the value of public intervention is therefore structured by the importance of these network externalities.

What can we say about public intervention in this context? Even though two-sided markets have specific characteristics, traditional anti-trust issues persist. The definition

\footnotetext{
${ }^{53} \mathrm{~A}$ similar point is made by d'Annunzio (2017) for investment in premium content in TV market.

${ }^{54}$ See also Cabral (2020) for an interesting perspective on merger policy in digital markets, with a focus on innovation.
} 
of markets or the measure of competition need to be analyzed/interpreted differently in a two-sided market compared to a standard market, especially when involving a nexus of markets. Once the necessary adaptations have been made-and the economic literature has greatly progressed in this area-it seems quite possible to think about competition policy in the case of platforms with the same philosophy as in standard markets. In particular, when activities involve relatively small network effects, standard anti-trust analysis can be adapted to account for the specificity of platforms and new theories of harm.

If network effects are large, the question is more intricate. Preserving dynamic competition for the market may require some pro-active intervention. In this regard, we should point out that tipping in digital markets may not resemble a natural monopoly as encountered in infrastructure markets. Large heterogeneity and low entry cost imply that while there may not be room for two large platforms, there are usually niche opportunities for small platforms, which may have the potential to challenge the incumbent. One of the risks associated with a lenient competition policy is that the dominant firm may stifle or buy all the small platforms likely to replace it as the dominant platform. It is important that the sector, even if characterized by significant network effects, allows innovation and the diffusion of innovation. On this front, the ability of consumers to multi-home has been underlined in the literature as important. Even if this behavior slightly decreases the gains of successful entry for a new platform, multi-homing facilitates entry and thus preserves the competitive dynamics without sacrificing too much efficiency.

One potential lesson from these various theory papers is that there can be a number of complex factors affecting the incentives of platforms and market analysis. This raises an interesting legal question around the standard of proof. When it is understood that a large incumbent platform faces complex and potentially anticompetitive incentives-different than less established platforms-should anticompetitive incentives be demonstrated by the authorities, or should the platform evidence a claim of 'no anticompetitive effect'? ${ }^{55}$

For competition policy, the issues of software interoperability and data sharing need more investigation. ${ }^{6}$ For instance, some people have claimed that data can be a source of incumbency advantage (the interested reader can find a discussion of this in Biglaiser, Calvano and Crémer, 2019). The current policy moves and proposals to allow data portability can be seen as the consequence of these ideas, where data is considered as a key input for firms to compete on a market. But the impact on the platform's initial offer of such a measure -which amounts to giving more ownership rights over data to consumers- is far from being clear.

\footnotetext{
${ }^{55}$ We thank a referee for pointing this potential link between complexity and burden of proof.

${ }^{56}$ See Hagiu and Wright (2020), and Prüfer and Schottmüller (2017) for the analysis of data sharing in the context of data-driven learning by doing. See also Condorelli and Padilla (2020) for competition policy implications of data-driven envelopment strategies.
} 
While our article has focused mostly on price competition, non-price dimensions become increasingly the locus of competition, in particular as part of the "economics of free". This implies for instance incorporating product design or information management (recommendations, ratings and feedback systems, marketing.....) in the antitrust practices. Most importantly, behavioral and psychological factors seem to play a key role for many platforms. ${ }^{[7}$ Research on these factors and their implications for the conduct of competition policy for digital platforms should be of prime importance.

\section{References}

Affeldt, P., Filistrucchi, L., and Klein, T.K. (2013). "Upward pricing pressure in two-sided markets", The Economic Journal 123.572: F505-F523.

Ambrus, A., and Argenziano, R. (2009). "Asymmetric networks in two-sided markets", American Economic Journal: Microeconomics, Vol. 1.1: 17-52.

Amelio, A., Giardino-Karlinger, L., and Valletti, T. (2020). "Exclusionary Pricing in TwoSided Markets", International Journal of Industrial Organization, Forthcoming.

Amelio, A., and Jullien, B. (2012). "Tying and freebies in two-sided market", International Journal of Industrial Organization, Vol. 30(5), 436-446.

Anderson, S. P., and Coate, S. (2005). "Market provision of broadcasting: A welfare analysis", The Review of Economic Studies, Vol. 72(4), 947-972.

Anderson, S. P., Foros, Ø., and Kind, H. J. (2019). "The importance of consumer multihoming (joint purchases) for market performance: Mergers and entry in media markets", Journal of Economics \& Management Strategy, Vol. 28(1), 125-137.

Anderson, S. P., Foros, O., and Kind, H.J. (2017). “Competition for advertisers and for viewers in media markets", The Economic Journal, Vol. 128, 34-54.

Anderson, S. P., Foros, Ø., Kind, H. J., and Peitz, M. (2012). "Media market concentration, advertising levels, and ad prices", International Journal of Industrial Organization, Vol. 30(3), 321-325.

Anderson, S. P., and Peitz, M. (2020). "Media see-saws: Winners and losers in platform markets", Journal of Economic Theory, Vol. 186, 1049-90.

Argentesi, E., Buccirossi, P., Calvano, E., Duso, T., Marrazzo, A. and Nava, S. (2019). Expost Assessment of Merger Control Decisions in Digital Markets, LEAR report for the Competition and Market Authority (CMA).

Argentesi, E, and Filistrucchi, L. (2007). "Estimating Market Power in a Two-Sided Market: The Case of Newspapers", Journal of Applied Econometrics, Vol. 22(7), 1247-1266.

\footnotetext{
${ }^{57}$ See the discussion in Scott-Morton (2019).
} 
Armstrong, M. (2006). "Competition in Two-Sided Markets", RAND Journal of Economics, Vol. 37(3), 668-691.

Armstrong, M., and Vickers, J. (2001). "Competitive Price Discrimination", RAND Journal of Economics, Vol. 32(4), 579-605.

Armstrong, M., and Wright, J. (2007). “Two-sided Markets, Competitive Bottlenecks and Exclusive Contracts", Economic Theory, Vol. 32(2), 353-380.

Aymanns, C., Dewatripont, M., and Roukny, T. (2019). "Vertically Disintegrated Platforms", Available at SSRN 3507355.

Bakos, Y., and Brynjolfsson, E. (1999). "Bundling Information Goods: Pricing, Profits and Efficiency", Management Science, Vol. 45(12), 1613-1630.

Belleflamme, P., and Peitz, M. (2015). Industrial Organization, Cambridge University Press.

Belleflamme, P., and Peitz, M. (2019). "Platform competition: Who benefits from multihoming?", International Journal of Industrial Organization, Vol. 64, 1-26.

Belleflamme, P., and Toulemonde, E. (2009). "Negative intragroup externalities in twosided markets", International Economic Review, Vol. 50(1), 245-272.

Berhinger, S., and Filistrucchi, L. (2015). "Areeda-Turner in Two-Sided Markets", Review of Industrial Organization, Vol. 46(3), 287-306.

Bernheim B.D., and Whinston, M.D. (1998). "Exclusive Dealing”, Journal of Political Economy, Vol. 106(1), 64-103.

Biglaiser, G., Calvano, E., and Crémer, J. (2019). "Incumbency advantage and its value", Journal of Economics \& Management Strategy, Vol. 28(1), 41-48.

Biglaiser, G., and Crémer, J. (2020). "The value of incumbency in heterogeneous platforms", American Economic Journal: Micro, forthcoming.

Biglaiser, G., Crémer, J., and Dobos, G. (2013). "The value of switching costs", Journal of Economic Theory, Vol. 148(3), 935-952.

Biglaiser, G., Crémer, J., and Veiga, A. (2020). "Migration between platforms”, TSE Working Paper, n. 19-1038.

Boik, A., and Corts, K. S. (2016). "The Effects of Platform Most-Favored-Nation Clauses on Competition and Entry", Journal of Law and Economics, 59(1), 105-134.

Bolton, P., Broadley, J., and Riordan, M. (1999). "Predatory pricing: strategic theory and legal policy", Georgetown Law Journal, Vol. 88, 2239-2330.

Bolton, P., and Scharfstein, D. S. (1990). "A theory of predation based on agency problems in financial contracting", The American economic review, Vol. 80(1) 93-106. 
Cabral, L. (2011). "Dynamic price competition with network effects", The Review of Economic Studies, Vol. 78(1), 83-111.

Cabral, L. (2020), "Merger policy in digital industries", Information Economics and Policy, forthcoming.

Cabral, L., and Riordan, M. (1994). "The learning curve, market dominance, and predatory pricing", Econometrica, Vol. 62(5), 1115-1140.

Cabral, L., and Riordan, M. (1997). "The learning curve, predation, antitrust, and welfare", The Journal of Industrial Economics, Vol. 45(2), 155-169.

Caillaud, B., and Jullien, B. (2001). "Competing cybermediaries", European Economic Review, Vol. 45(4-6), 797-808.

Caillaud, B., and Jullien, B. (2003). "Chicken \& Egg: Competition among intermediation service providers", RAND Journal of Economics, Vol. 34(2), 309-328.

Calvano, E., and Polo, M. (2020). "Strategic differentiation by business models: Free-toAir and Pay-TV", The Economic Journal, Vol. 130, 50-64.

Carroni E., Madio, L. and Shekhar, S. (2019). "Superstars in two-sided markets: exclusives or not?", CESifo working paper 7535.

Casadesus-Masanell, R., and Hervas-Drane, A. (2015). "Competing with privacy", Management Science, Vol. 61(1), 229-246.

Chandra, A., and Collard Wexler, A. (2009). "Mergers in two-sided markets: An application to the Canadian newspaper industry", Journal of Economics \& Management Strategy, Vol. 18(4), 1045-1070.

Choi, J.P. (2010). "Tying in two-sided markets with multi-homing", Journal of Industrial Economics, Vol. 58 (3), 607-626.

Choi, J.P., and Jeon, D.S. (2020). "A Leverage Theory of Tying in Two-Sided Markets", American Economic Journal: Microeconomics, forthcoming.

Choi, J.P., Jullien, B., and Lefouili, Y. (2017). “Tying in Two-Sided Markets with Multi?Homing: Corrigendum and Comment", Journal of Industrial Economics, Vol. 65 (4), 872-886.

Condorelli, D., and Padilla, J. (2020). "Harnessing Platform Envelopment in the Digital World". Journal of Competition Law \& Economics, forthcoming.

Cosnita-Langlais, A., Baranes, E., and Cortade, T. (2016). "Merger control on two-sided markets: is there need for an efficiency defense?", No. hal-01668515.

Correia da Silva, J., Jullien, B., Lefouili, Y., and Pinho, J. (2019). "Horizontal mergers between multisided platforms: Insights from Cournot competition", Journal of Economics E Management Strategy, Vol. 28(1), 109-124. 
Crémer J., de Montjoye, Y.-A., and Schweitzer, H. (2019). Competition Policy for the Digital $E r a$, report for the European Commission (DG Competition).

Crémer J., Rey P., and Tirole J. (2000). "Connectivity in the commercial internet”, Journal of Industrial Economics, Vol. 48, 433-472.

De Cornière, A., and Taylor, G. (2014). "Integration and search engine bias", RAND Journal of Economics, Vol. 45 (3), 576-597.

De Cornière, A., and Taylor, G. (2019). “Upstream Bundling and Leverage of Market Power", TSE Working Paper, n.17-827.

De Cornière, A., and Taylor, G. (2020). "Data and Competition: a General Framework with Applications to Mergers, Market Structure, and Privacy Policy", TSE Working Paper, n. 20-1076.

D'Annunzio, A. (2017). "Vertical integration in the TV market: Exclusive provision and program quality", International Journal of Industrial Organization, Vol. 53, 114-144.

Dewenter, R., Haucap, J., and Wenzel, T. (2011). "Semi-collusion in media markets", International Review of Law and Economics, 31(2), 92-98.

Doganoglu, T., and Wright, J. (2006). "Multi-homing and compatibility", International Journal of Industrial Organization, Vol. 24(1), 45-67.

Doganoglu, T., and Wright, J. (2010). "Exclusive dealing with network effects", International Journal of Industrial Organization, Vol. 28 (2), 145-154.

Edelman, B. and J. Wright (2015) "Price Coherence and Excessive Intermediation", Quarterly Journal of Economics, 130(3), 1283-1328.

Eisenmann, T., Parker, G. and Van Alstyne, M. (2011). "Platform envelopment", Strategic Management Journal, Vol. 32(12), pp.1270-1285.

Evans, D.S. (2013). "Economics of Vertical Restraints for Multi-Sided Platforms", University of Chicago Institute for Law \& Economics Online Research Paper No. 626.

Evans, D.S. (2017). "Why the dynamics of competition for online platforms leads to sleepless nights but not sleepy monopolies", SSRN 3009438.

Evans, D.S., and Noel, M.D. (2008). "The Analysis of Mergers that Involve Multisided Platform Business", Journal of Competition Law and Economics, Vol. 4(3), 663-695.

Farrell, J., and Klemperer, P. (2007). "Coordination and lock-in: Competition with switching costs and network effects" in Handbook of industrial organization, Vol. 3, 1967-2072.

Farrell, J., and Saloner, G. (1985). "Standardization, Compatibility, and Innovation", RAND Journal of Economics, Vol. 16 (1), 70-83.

Filistrucchi, Lapo. (2018). "Market definition in multi-sided markets." In Rethinking antitrust tools for multi-sided platforms, OECD. 
Filistrucchi, L., Geradin, D., Van Damme, E., and Affeldt, P. (2014). “Market definition in two-sided markets: Theory and practice", Journal of Competition Law \& Economics, Vol. 10(2), 293-339.

Foros, Ø., Kind, H. J., and Sørgard, L. (2015). Merger policy and regulation in media industries. In Handbook of Media Economics (Vol. 1, pp. 225-264). North-Holland.

Fumagalli, C., and Motta, M. (2018). "Dynamic Vertical Forclosure", mimeo.

Franck, J.U., and Peitz, M. (2019). Market Definition and Market Power in a Platform Economy, CERRE Report.

Furman, J., Coyle, D., Fletcher, A., McAules, D., and Marsden, P. (2019). Unlocking digital competition: Report of the digital competition expert panel. Report prepared for the Government of the United Kingdom.

Gans, J. (2019). “The Specialness of Zero", NBER Working Paper 26485.

Hagiu, A., and Halaburda, H. (2014). "Information and two-sided platform profits", International Journal of Industrial Organization, Vol. 34, 25-35.

Hagiu, A., and Spulber, D. (2013). "Integration First-Party Content and Coordination in Two-Sided Markets", Management Science, Vol. 59 (4), 933-949.

Hagiu, A., and Wright, J. (2014). “Marketplace or reseller?", Management Science, Vol. 61(1), 184-203.

Hagiu, A., and Wright, J. (2020). “Data-enabled learning, network effects and competitive advantage", Working Paper.

Halaburda, H., Jullien, B., and Yehezkel, Y. (2020). "Dynamic competition with network externalities: Why history matters", The RAND Journal of Economics, 51(1), 3-31.

Hurkens, S., and Lopez, A. (2014). "Mobile Termination, Network Externalities and Consumer Expectations", The Economic Journal, Vol. 124, 1005-1039.

Johnson, J. P. (2017). "The Agency Model and MFN Clauses", The Review of Economic Studies, 84(3), 11511185.

Jullien, B. (2011). "Competition in multi-sided markets: Divide and conquer", American Economic Journal: Microeconomics, Vol. 3(4), 186-220.

Jullien, B., and Pavan, A. (2018). "Information management and pricing in platform markets", The Review of Economic Studies, Vol. 86(4), 1666-1703.

Karle, H., Peitz, M., and Reisinger, M. (2020). "Segmentation versus Agglomeration: Competition between Platforms with Competitive Sellers", Journal of Political Economy, Vol. 128(6), 2329-2374.

Karlinger, L., and Motta, M. (2012). "Exclusionary Pricing When Scale Matters", Journal of Industrial Economics, Vol. 60 (1), 75-103. 
Kaplow, L. (2018). "Recoupment, Market Power, and Predatory Pricing", Antitrust Law Journal, Vol. 82.

Lee, R. S. (2013). Vertical integration and exclusivity in platform and two-sided markets. American Economic Review, 103(7), 2960-3000.

Lefouili, Y., and Pinho, J. (2020). "Collusion between Two-Sided Markets", TSE working paper 18-894.

Leonello, A. (2010). "Horizontal mergers in two-sided markets", European University Institute mimeo.

Markovich, S., and Yehezkel, Y. (2019). “Group Hug: Platform Competition with Usergroups", mimeo.

Miao, C.H. (2009). "Limited Compatibility in Two-Sided Markets", The Review of Network Economics, Vol. 8(4), 346-364.

Niels, G. (2019). "Transaction Versus Non-Transaction Platforms: A False Dichotomy in Two-Sided Market Definition", Journal of Competition Law \& Economics, Vol. 15, Issue 2-3.

Prat, A., and Valletti, T. (2019). "Attention Oligopoly", mimeo.

Prüfer, J., and Schottmüller, C. (2017). "Competing with Big Data", mimeo.

Rasmusen, E.B., Ramseyer, J.M., and Wiley, J.S. (1991). "Naked Exclusion”, American Economic Review, Vol. 81(5), 1137-45.

Reisinger, M. (2014). "Two-part tariff competition between two-sided platforms", European Economic Review, Vol. 68, 168-180.

Rochet, J.-C., and Tirole, J. (2003). "Platform competition in two-sided markets", Journal of the European Economic Association, Vol. 1(4), 990-1029.

Rochet, J.-C., and Tirole, J. (2006). "Two-sided markets: a progress report", RAND Journal of Economics, Vol. 37(3), 645-667.

Rubinfeld, D. L. (1998). "Antitrust Enforcement in Dynamic Network Industries", The Antitrust Bulletin, Vol. 43, 859-882.

Ruhmer, I. (2010). "Platform collusion in two-sided markets", mimeo, University of Mannheim.

Rysman, M. (2019). "The reflection problem in network effect estimation". Journal of Economics \& Management Strategy, 28(1), 153-158.

Segal, I. R., and Whinston, M.D. (2000). "Naked exclusion: comment", American Economic Review, Vol. 90(1), 296-309.

Scott-Morton, F. (2019). Report from the Committee for the Study of Digital Platforms Market Structure and Antitrust Subcommittee, Stigler Center, University of Chicago. 
Tan, G., and Zhou, J. (2017). "Price Competition in Multi-Sided Markets", Available at SSRN 3029134.

Vasconcelos, H. (2015). "Is exclusionary pricing anticompetitive in two-sided markets?", International Journal of Industrial Organization, Vol. 40, 1-10.

Wang, C., and Wright, J. (2020). "Search platforms: Showrooming and price parity clauses", The RAND Journal of Economics, Vol. 51(1), 32-58.

Weyl, G. (2010). "A price theory of multi-sided platforms", American Economic Review, Vol. 100(4), 1642-72.

Weyl, G., and White, A. (2016). "Insulated Platform Competition", Available at SSRN 1694317.

Whinston, M. D. (1990). "Tying, Foreclosure, and Exclusion", American Economic Review, Vol. 80(4), 837-859. 